\title{
Confronting a Darkening World: AMM at 50 Years-An Aesthetic Memorandum
}

\section{Edwin Prévost}

Informal 'sound' has a power over our emotional responses that formal 'music' does not, in that it acts subliminally rather than on a conscious cultural level. This is a possible definition of the area in which AMM is experimental. We are searching for sounds and for the responses that attach to them, rather than thinking them up, preparing them and producing them. The search is conducted in the medium of sound and the musician . . . is at the heart of the experiment. (Cardew 127)

In 1999 I returned from a jazz festival and colloquium in Guelph, Canada and decided to set up an improvisation workshop. This was to test, with others, if there was any continuing momentum and meaning in the kind of practice I had been part of, and subject to, within the ensemble AMM. The reputation of AMM might have been enough to encourage the curious. Whether a significant amount would stay the course and help explore and develop a unique theory of improvisation was another matter. Only time would tell whether I would become more (or less) convinced of the efficacy of this practice. That was sixteen years ago, and people are still coming. I have heard much music, learned things, and made many friends. The following is a brief historical account of how I perceived AMM and my consequent thoughts about the theoretical basis of our shared experiences and how this premise has been extended and applied to the continuing cohort that shares music at our London workshop meetings.

In 1965, four men in their mid-twenties began the musical explorations that became known as AMM. The following year, the avant-garde composer Cornelius Cardew, then in his early thirties, joined them. At the time, Cardew had recently relinquished his role as Karlheinz Stockhausen's assistant and was immersed in the development of his graphic magnum opus Treatise. These five musicians (Cardew, Lou Gare, Eddie Prévost, Keith Rowe, and Lawrence Sheaff) made AMM's first recording AMMMUSIC in $1966 .{ }^{1}$ The general trajectory of this phase of AMM's early history (as well as Cardew's experiences with Stockhausen) is well documented in John Tilbury's biography Cornelius Cardew: a life unfinished. ${ }^{2}$

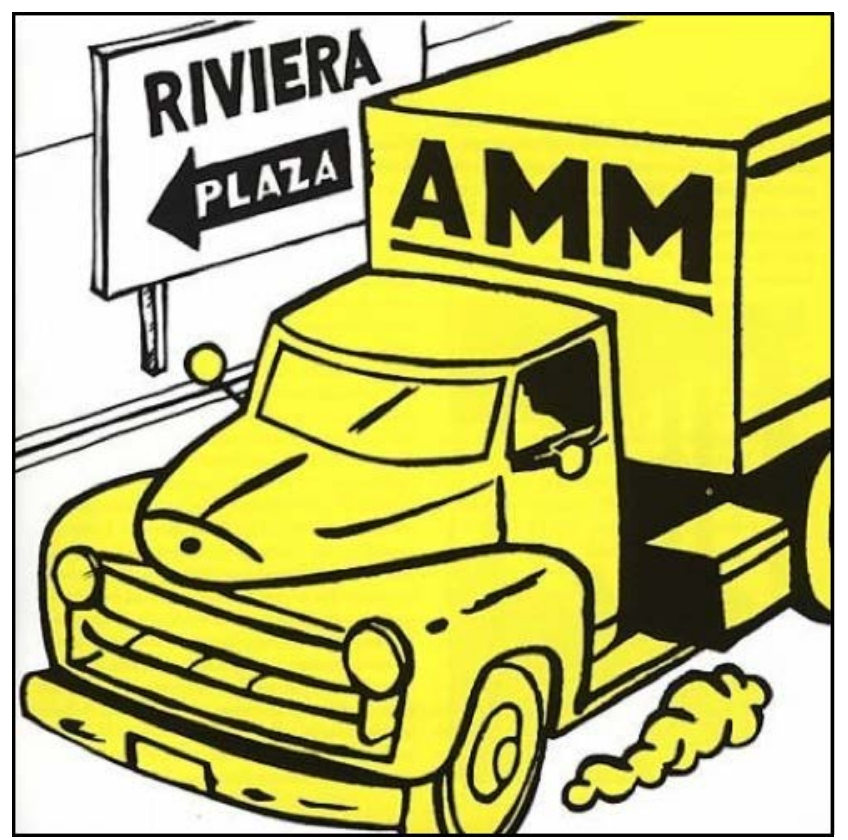

Click image above to listen to "After Rapidly Circling the Plaza" from AMMMUSIC. ${ }^{3}$ [Adobe software may be required.] 
It was a rapid learning curve for us all. Cardew's presence certainly aided our awareness (and possible significance) of the new ground we were breaking. Cornelius was to be a lasting influence on the theory and practice of AMM. This influence should not, of course, diminish the energy, creative thrust or theoretical insights arising from the rest of the ensemble: a band formed or led by Cardew would have been very different from AMM. It was, I suspect, the differences and the creative personalities issuing from this educationally and culturally disparate group of people that fascinated him--just as his unprecedented company invigorated the rest. By the early 1970s, however, the band had fractured and Cardew progressively moved away from the "then" new music (exemplified in Cage, Stockhausen, and improvisatory practices more generally) into his life as an active Marxist/Leninist/Maoist.

In 1981, Cardew was killed in a hit-and-run incident. This was during a period of tentative rapprochement where Cardew had rejoined AMM for some informal playing. His death shocked us all, yet life and AMM went on. The innovative work that had shaped our early years was maturing. Various AMM formulations emerged, but by the early 1980s, the ensemble had settled down to Prévost, Rowe, and Tilbury. With this maturity came a more confident and informed sense of what we were doing. This confidence arose as the ensemble became a significant part of the emergent aesthetic broadly referred to as "free improvisation."

By the mid 1980s, it was not unusual for AMM to participate in workshops and discussions about improvisation. On one such occasion, I addressed a conference convened at London University's Goldsmiths' College. I recall a muffled, scoffing sound coming from a (now) well-known contemporary music composer. My questioning of the priority of composing ${ }^{4}$ had elicited a visceral, inarticulate retort. The incident was representative of the dismissive and rather patronizing attitude improvisers met from many composers, including Luciano Berio, Pierre Boulez, John Cage, and Elliott Carter, as well as my pal at the Goldsmiths' conference. We (that is, the improvising community) needed to either ignore these responses to our work or face them out.

It was in my paper at Goldsmiths' where I first aired the twin analytical propositions of "heurism" and "dialogue" that, albeit reductively, seemed to inform the practice of improvisation. I was nonetheless aware that more needed to be done to develop a useful theory of improvisation. The essential negative critique was that "improvisers only play what they know." Improvisers needed help to find what Boulez described as "a primary form of material" (461). This comment suggests the improvising medium is not functionally capable of producing anything original or creative. I did not think these criticisms were meant to be helpful; Boulez, however, did have a point.

Help came from a close, if unexpected, source. My later editing of Cardew's published output, ${ }^{6}$ not unnaturally, led to a more careful reading of his thoughts. I found (from the quotation at the head of this memorandum) a hitherto unnoticed resonance with my own emergent twin analytical propositions, styled in a more poetical manner but theoretically aligned: "We are searching for sounds and for the responses that attach to them, rather than thinking them up, preparing them and producing them."

Two words govern the axiom: "we" is the socializing denominator (dialogue) and "searching" describes the proactivity (heurism).

Boulez and his ilk were not wrong about the creative dependence of most improvisations upon "existing" material. Most obviously, the majority of musical improvisations are (or are close to) analogues of previously heard or already conceived music-even if couched informally or in an avant-garde form. Such improvisations were as much a presentation of reflected upon material as a more formally or traditionally constructed composition might be. Boulez and company, however, were wrong about where "a primary form of material" must inevitably arise from-that is, through a more formal compositional method. Cardew's early observations about what distinguished AMM music from other forms of improvisation indicated that the "collective search" was prioritized (albeit inconsistently) over the "presentation" of considered material (127).

This collective search is the theoretical starting point for the London workshop I convened in 1999. Given that this approach is entirely contrary to how most Western classical and popular music is developed, I concede we might have to forego labelling what we do as "music." Cardew's observations were, of course, based upon an ensemble that (apart from himself) had no formal musical education. We were not "readers": the sounds we found and applied had a completely different relationship to the historical context of conventional music. In a workshop setting, I introduce these general propositions fairly slowly. I sense that not all comprehend what I say: one might hear the words, but not necessarily appreciate how directly I mean them or how I put them into practice. Some, it is plain from the responses and sonic output, are not listening to others and some are clearly not searching. Most of us fail to do this consistently, including myself. 


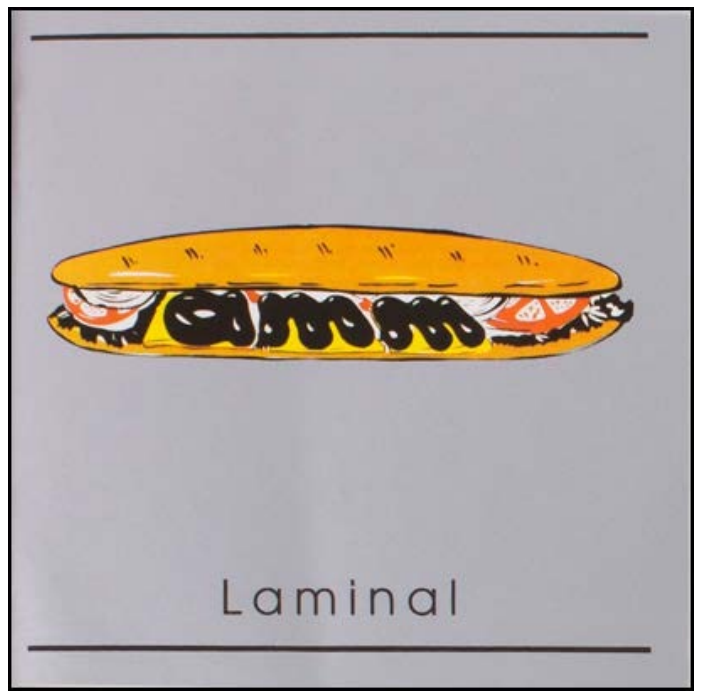

Click image above to listen to "The Great Hall" from disc 2 of Laminal. ${ }^{7}$ [Adobe software may be required.]

Does this theory of collective searching have a good reason for being? Cardew's early observation of the "possible definition of the area in which AMM is experimental" (127) can be corroborated by my playing techniques-in which there remains a strong exploratory component-and our workshop experiences. My definition of this demands (at least) two things:

a) Treating the materials for making sounds with continuous curiosity.

b) Attending to all other ambient sounds and, in particular, those from collaborating participants.

In practice, this means "meta-musicians" work to discover what the instrument or sound-source can develop: they push, pull, theorize, and test. ${ }^{8}$ Often, the results are surprising and spectacular, and sometimes not-serendipity. An "awkward wealth" can emerge, the player hardly knowing what to do with it. All this is done within a collective ambience of potentially awkward responses from other musicians.

It is from these sources that we can derive primary material, a way of developing a personal repertoire independent of "received thinking" and the regressive repetitiousness of self-plagiarism. This form of creative development contrasts with the general assistance offered by a composition, set in motion either by musicians themselves and presented in performance, or by another source. "Written compositions," as Cardew notes, "are fired into the future; even if never performed, the writing remains as a point of reference" (126).

The sonic existence, temporality, and cultural meaning of a musical composition can only be anchored by the external decision to perform it. Performing a written composition uses primary material derived from the thoughts of others that is inevitably detached from the wider circumstances of whatever occasions a performance.

Perversely, such material only remains primary for a short while; once used, it immediately becomes secondary. Performance decisions using external sources - no matter how creatively "interesting"-become invested with notions of authority. You might think the creative watchword for an improviser is autonomy, but the situation is far more complex. Humans are dependent upon the sociobiological structures that configure our species: we are social beings.

Music is specific to human beings. Other species may make sounds we find musical, but no matter how beautiful and satisfying, those sounds are inextricably bound up in their own biological context. ${ }^{10}$ Likewise, with Homo Sapiens music tells us something about our humanity. Despite the risk of mythologizing human biology, we can ground these suggested operative procedures—observed and intuited by Cardew-within recent evolutionary biological thinking. Human cognitive make-up is a tantalizing mixture of technical and social domains composed of both organs and instincts that give us the ability to survive. Our collective technical prowess is nestled within concomitant social skills. It is the enhancement, refinement, and understanding of these faculties that make us potentially more human.

To repeat, two words govern Cardew's axiom: "we" is the socializing denominator and "searching" describes the pro-activity. In such a schema, we may become mythmakers, because there is a pungent almost deterministic quality detectable in this kind of reductionism. Is it too good to be true? 


\section{Reductionism}

Readers might feel, given the singularity of this general proposition, that I have reduced an activity of informal music making to such a basic level of abstraction as to render it meaningless. My defence, however, is that reductionism is a tool for understanding: it may not fully expose a reality, but we look for it through as many observational and imaginative prisms as possible. It might, I suggest, be useful not to overuse Karl Popper's program for truth where confuting the smallest attendant fact necessarily disproves the whole theory. It just might be, in the case of our collective searching procedure, that we have hit upon an idea that transcends the lazy general perceptions of what music is for, given that most people think music has no meaning, apart from some mythical idea of high culture or as something to dance to (although the desire for bodily movement may well have its roots in some biological imperative).

Whence high culture? This is not an objective condition. Neither is pop culture. High culture is a figment of our collective imagination, heavily imbued with the value system of our present hierarchy: it has in recent years turned its face from the old ruling class hegemony and their fetishes and become increasingly reflective of the current phase of market capitalism. Look hard at the schedules for the annual BBC Proms: there is now, inevitably, a growing infiltration of postmodern and popular culture into their repertoire. Anyone who defends this state of affairs is simply unconsciously complicit in collective subjectivity. Those with similar feelings and ideas tend to get into lockstep, surrendering their own intellectual and emotional autonomy for the comfort of an agreeing cohort.

Ideas come from somewhere-but nowhere certain. They may simply be the products of linguistic determinism: bright, shiny, and unique, just begging to be true. Conversely, ideas might be enriched cognitive material derived from some connection with our human actions that, even if implausible or awkward, can produce something new and positive. The question is whether my counter-theory too is anything more than an unrealizable myth.

This theory, I believe, is saved through observation of the exigencies of practice. It has been my experience that if I encourage searching, there is a tendency for the more empathic skills to be sidelined. Conversely, close attention to the output and imagined mind-theory of others is often at the expense of investigatory competence. At a workshop in Norway a few years ago, I asked a group of music students to search collectively. The approach was new to them, and I noticed that the young men (mostly), freed perhaps from the normal constraints of musical expectations, found themselves enmeshed in a self-absorbed frenzy of experimentation. This was at the expense of any sense of awareness or empathy for those with whom they were cohabiting in this musical space. Not exactly satisfactory. Concurrently (and at the risk of gender stereotyping), I thought I detected (mostly) in the female musicians a greater tendency to collaborate with others rather than investigate. Also, not entirely satisfactory.

The cognitive archaeologist Steven Mithen offers a bold idea about the nature of human creativity to explain this trend to my reserved satisfaction. He suggests human creativity maybe owes its-albeit fluctuating-condition to the integration of human technical (heuristic) and social (dialogical) domains-one form of intelligence seeping (as it were) into the other. The key element in this proposition is that the condition of cognitive fluidity is intermittent. What we describe (mythologize) to ourselves as the somewhat erratic emergence of inspiration could simply be a stuttering, fitful evolutionary condition, a loose connection. Whatever is the acceptable description of what is going on, one thing seems plain: a situation such as I have described qualifies as "experimental." As I have hinted above, however, such a situation is also a socially qualified sense of experimental autonomy: "The search is conducted in the medium of sound and the musician . . . is at the heart of the experiment."

As direct, bold, and as lucid as his prose is, we readers have perhaps allowed some implications of Cardew's thinking to pass over our heads. He also suggests that sound "has a power over our emotional responses ... that it acts subliminally rather than on a conscious cultural level" (127).

His words, even if initially unheeded, suggest a quiet paradigm shift. All sentient beings respond to external stimuli. The adaptive imperative is central to our continued existence as a species and we have, to an extraordinary extent, encultured these fundamental responses. Fear and foreboding, joy and anticipation now inform our emotional lives beyond life-threatening or life-enhancing moments. These emotions are, for many, the stuff of art. We have the capacity to convert the subliminal into the sublime: the hidden can be made explicit.

Implicit in Cardew's recognition that AMM's modus operandi was "searching" is the attendant imperative towards a new sense of "listening." If the musical operating levers are different from conventional music making, then it follows that the consequent "meaning" we observe, acknowledge, and invest in these sounds is likely to be subject to a different value system. Emphasis is varied, but the Italian Futurists, Edgar Varèse, John Cage, and Pauline Oliveros also enjoin us to listen differently. John Tilbury helpfully explains his own way around this aesthetic shift in his liner notes to my CD Material Consequences: 
Over the years, and specifically through my involvement, in particular with Cardew, Feldman and AMM, I have come to "hear" classical music, for example, differently. Even with painting I "see" the work of Vermeer, for example, differently, probably radically so. The mimetic aspects— the "recognizable" maid, lute, basket, fruit, etc.-although represented with staggering technical aplomb, are for me virtually immaterial in my appreciation, which seems to transcend these technical aspects. In other words, as a viewer I do not feel the need for an intellectual, cultural or historical adjustment when I move from a Vermeer to a Rothko, and I find, or rather feel, that they have much in common.

John Tilbury's view through a $21^{\text {st }}$-century lens may be unhistorical (and even ahistorical). It reflects his modernism. He knows we cannot superimpose a modernist view on the mindset and output of a $17^{\text {th }}$ century Dutch artist. While it is not possible to invest Vermeer with a proto-modernist perspective, surely his art reveals an appreciation and an active concern with texture and colour equal to the most assiduous of abstract painters. These are essential working characteristics of the modernist and experimental enquiry, features fundamental to AMM even though we may have flirted with some ambiguities in this regard. A functioning exploratory musical philosophy is bound to be messy and even reactive at times; to demand a representative or narrative reference for a Mark Rothko painting, however, clearly misses the point.

As with music, any overt resemblance to old forms risks some kind of regression. There may be problems, for example, understanding why Keith Rowe has, in later times, compared his role with AMM to the continuum of Baroque music. His consequent reported association of some aspects of his playing with Mozart seems perverse and confusing, coming from someone so uniquely creative. This observation could act to obscure the exploratory innovations of his music within their attendant social, technical, and political implications, suggesting some uncertainty about lending his work wholly to a new cultural order. Some listeners have no such doubts in reading AMM - with Keith Rowe's contributions and Tilbury's and Prévost's responses in mind. One listener at an AMM concert recalled a poignant remark from Theodor Adorno: "The darkening of the world makes the irrationality of art rational: radically darkened art" (19).

And yet there are problems with this characterization. The Crypt (1968) is for Rowe the quintessential AMM recording, arguably our most uncompromising and austere. In my view, it is indisputably experimental. How do we read Rowe's subsequent perspective? The Crypt was made before the collapse of The Scratch Orchestra (co-founded by Cardew) and the fracture in AMM during the early 1970s. By the time Rowe re-entered AMM in the late 70s, the ensemble was re-configured to include John Tilbury. Obviously, Tilbury along with Cardew had been at the forefront of an earlier foray into post Second World War British musical experimentalism, bringing the work of Cage, Feldman, Brown, and Wolff (in particular) to the attention of London audiences. One could argue that AMM's experimental credentials were second to none, but that is to ignore the early waves of the postmodern tide beginning to wash over our economy and cultural landscape. We cannot claim to have kept our experimental powder entirely dry. ${ }^{11}$

Was Keith Rowe trying to link past and established formulations to aesthetically alien material? The postmodern preoccupation with mining the past appears to be the principal response to contemporary musical problems. We could read Keith's references to the Baroque and Mozart as a satirical slap at postmodernism-his rear-view mirror reflecting an equally distorted image of the past. After all, the violent and crude abstractedness of The Crypt, which offends many ears, has a surreal effect. Its sound world is light years away from any embodiment of the Baroque. I think, however, that Rowe's Baroque and Mozart affiliations are most prominent in his post-AMM work. Certainly, his controversial Hands of Caravaggio CD seems to emphasize a determination to draw parallels, inspiration, and possible cultural kudos from such referencing. ${ }^{2}$ This emphasis, it seems to me, is the ultimate postmodern refuge for the disillusioned experimentalist. Compositional re-rendering of Henry Purcell's music and claims to Baroque influence on electronic improvisations are surely incompatible with any sense of progressive, contemporary culture. Each is a conscious detachment from modernism, evoking the authority and atmosphere of another place and time.

\section{A Note on Postmodernism}

The postmodern idea gained wider currency in Western culture during the late $20^{\text {th }}$ century, perhaps mostly apprehended through the application of a whimsical neo-classical architecture. This became framed as a response to modernism. Details of classical architecture adorned new buildings without need or desire to follow the inherent structural raison d'être of their classical origins. Reinforced concrete, steel, glass, plastics and carbon fibre offered a different (modern) building paradigm. Modern materials and the attendant science and technological developments suggested and inspired different design options. It is the available science that leads to possible proportions and newly configured senses of elegance. The associative iconic cultural collateral of Greek art and philosophy and Roman imperial magnificence-which had been handed down by the European Renaissance-offered as 'add-ons' gave the client a satisfying psychological complex. This was in stark contrast to Le Corbusier's "machine for living" or the cold comfort of Brutalist architecture. 
Postmodernism took off. Whimsy was closely followed by the pragmatism of new market preference. What was almost a joke assumed a more serious mien. The paradox: modern building materials and techniques made to mock structures of another time and place. This practice began to infiltrate other modes of discourse, embracing (among many others) art, literature, and of course music. We entered a heightened state of iconic appearances: eclecticism on speed, fueled at times by unconscious irony. Serialism and experimentalism in musiccondemned (justifiably ${ }^{13}$ ) as elitist and inhospitable to musicians and audiences alike-were demoted in favour of an aesthetics of pastiche.

In jazz, Coltrane sound-alikes, Mingus tributes, and mock-Monk took hold. Jazz has perhaps always been conflicted about its past and present. With much of its roots embedded in vaudeville, it has an uncertain view of itself as art-if we accept that art has to be transformative. The wonderful interpretations of "the great American songbook"-which have made for superlative popular music-owe much to the creativity of jazz musicians. These cherished icons of the past should be appreciated and understood, but I fear that they have become a burden or a substitute for creative development.

New Age wasn't new in any way except for how it advertised already well-worked material as mood music and leisurely meditation. This rebranding resonated with the more respectable output of Arvo Pärt and Henryk Gorecki: it was tonally safe and amenable, achieving the eclectic's quest for nostalgia while culturally making the best of what was readily available.

We are all prone to a biased reading of history: "facts" and "their interpretative priority" are contentious. Margaret Thatcher's demotion of the idea of history being a worthwhile subject for study, however, and Fukuyama's suggestion of the "end of history," meant for some that we had reached "The endpoint of mankind's ideological evolution and the universalization of Western liberal democracy as the final form of human government" (4).

We were being asked to forget possible futures. Is the current situation as good as it can ever get?

The neo-conservatism and the postmodern share a similar linguistic construction. Both refer-even if obliquelyto other times and other ideas. In its most extreme form, the "new" conservatism (when it does attend to history) is more at home reflecting upon European $17^{\text {th }}$ and $18^{\text {th }}$ century merchant adventurers. These were critical elements in Western European capital development-a time of pirates and slavers financing the Industrial Revolution. ${ }^{14}$ Neo-conservatism is also keen to follow Lockean recommendations to support the moral philosophical priority of private property (more on this later).

Paradoxically, the "post" of postmodernism gives it a deceptive forward thrust, suggesting development from or replacement. Ultimately, postmodernism defines itself by what it is not: it is nostalgic eclecticism that reviews everything on the artistic and cultural horizon as potential material. John Oswald's Plunderphonics, ${ }^{15}$ describing his approach to collage, is a perfect linguistic riposte to the situation upon which he takes satirical revenge: the extremes reached in the marketization of culture. The postmodern is an inherent and systematic kind of cultural piracy.

Postmodernism ultimately reveals a loss of autonomous aesthetic confidence. Postmodern music-and many of its early protagonists had affiliations with experimentalism-appeals to a passive audience thankfully relieved from the duties of discernment. ${ }^{16}$ I recall my brief time with the Merce Cunningham Dance Company during their 1998 season at London's Barbican. Teetering on the cusp of commercial and critical acclaim, the company's management was clearly divesting its founding experimental credentials in the face of visible courting by emergent "professional" music creators. Their invitation to include me in the sound team, alongside Takehisa Kosugi and Jim O'Rourke, was clearly a mistake. Kosugi faithfully modulated his analogue electronics comfortably "in tune" with Jim's digital treatment of the James Bond theme. ${ }^{17}$ Novel it may have been; experimental it was not. Meanwhile, I remained stoically unreconstructed: searching, sawing away at my bowed tam-tam. The body language of Kosugi and Jim made it clear my contribution was not to their taste. I was not asked back. I cherish, however, the moment when I looked up from my place in the orchestra pit and saw a gleeful Merce motioning approval my way from his usual place in the wings.

Jazz has often been in an unwittingly innocent postmodern state due to its references to the past-by way of the popular song-and unprepossessing self-referencing "quoting." Much of what I have heard of the New York based Lincoln Center project, curated and produced by Wynton Marsalis, falls into a more self-conscious category. This initiative is aggressively postmodern, suggesting a self-satisfied stasis happy to consolidate the innovative gains of the "jazz masters."

Contrast this with the wildly confident, uninhibited, unconventional output of Sun Ra: cod-Egyptology ${ }^{18}$ and fantastic sci-fi interwoven with joyous popular song; shades of free music together with big band jazz in a circus extravaganza; an -ism-busting complex whose archness audaciously defied categorization; an otherworldly postmodernism unconcerned with market motives. With extravagant costumes and fantastic 
ideology as soul-preserving strategies, the Arkestra remained firmly outside of the newly emerging black, middle class aspirational nexus. Sun Ra proved to be an exceptional exception. ${ }^{19}$ The general ethos of jazz now fully embraces the need to be understood and popular: it measures success by how well it commands the market. In Britain, there is even a Houses of Parliament Jazz Award. Need one say more?

The freer edges of the improvisation continuum are no less subject to postmodern momentum. Free jazz works in well-measured grooves of its own, periodically moving into very defined and divisive aesthetically prescribed responses. In these far reaches of the musical constellation, market responsiveness and acceptability figure more strongly than one would wish. I recall Evan Parker sounding me out on AMM's Newfoundland album. ${ }^{20} \mathrm{His}$ jocular teasing feathered the thrust of his aesthetic acumen: "A little bit New Age, Ed?" I leave others to decide, but it made me think: few breathe freely in the thin atmosphere of the postmodern.

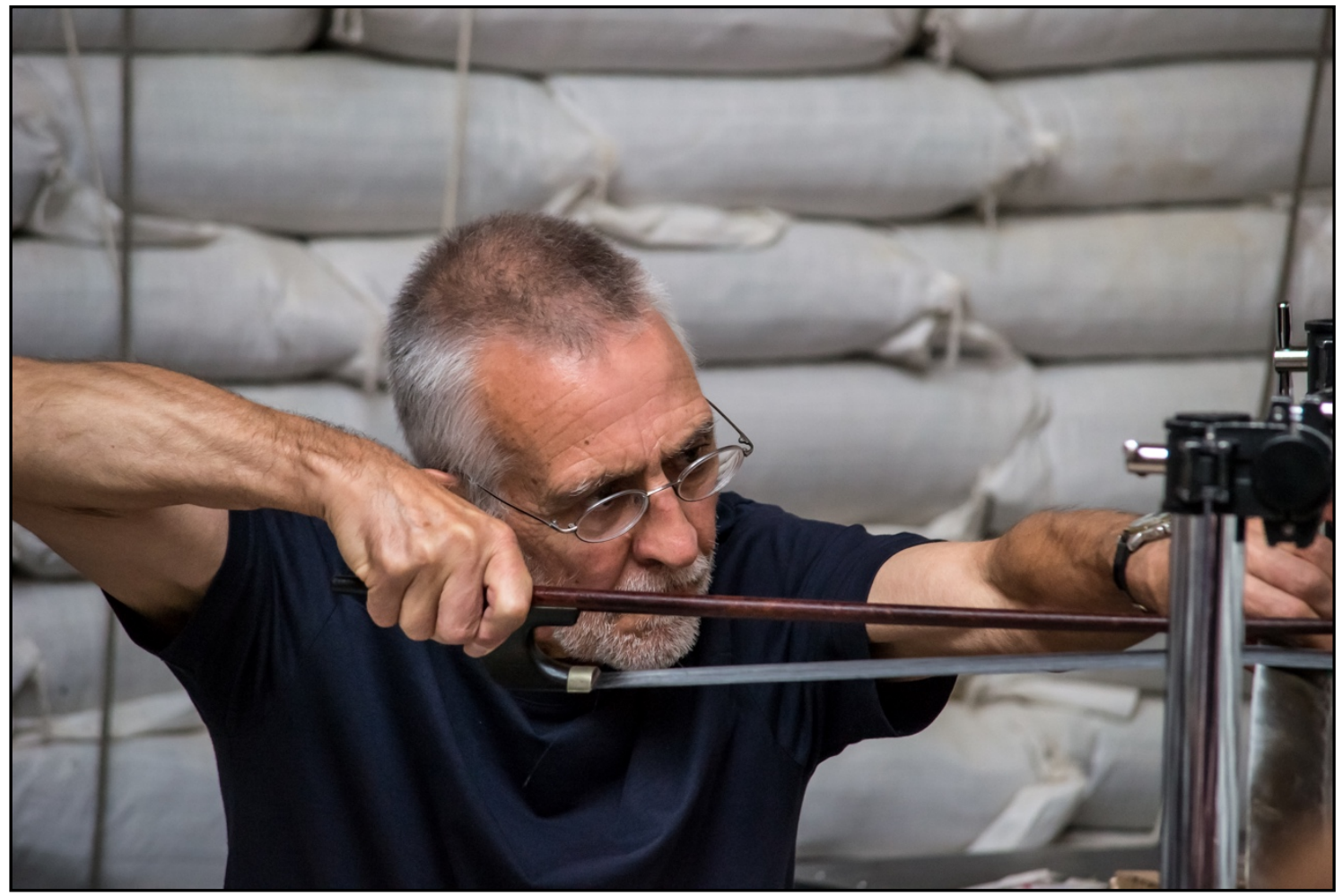

Eddie Prévost in performance

Perhaps AMM was not quite as inherently unreconstructable as we hoped. But we did broadly abstain from the pressures to shift ideological allegiances. How did other examples of the experimental music world fare, especially those closer to the improvisational schools unaffiliated with the burgeoning academic market in modern music? ${ }^{21}$ State funding is a good compass for locating ideological focus. Until the mid-1970s, even the Arts Council of Great Britain partially reflected modernist tendencies. This evaporated with the placement of business minds in our major arts institutions and in the Arts Council's administration. Out went artist advisory boards; in came a cadre of arts managers and style-conscious "curators" proudly bearing academic awards (from newly created degree programs in arts administration) and promising to do the bidding of their neo-conservative political masters.

Postmodernism was a necessary invention for the marketization of the arts, at which point state funding was effectively withdrawn from anything other than the self-serving mores of the neo-con project: bums on seats and marketability became the new watchwords. Free improvisation, which always was at the edges of anything remotely served by state funding, thus became an even more self-sustaining community, although not as fully conscious of its own aesthetic priority or its cultural position as I would like-hence this memorandum.

There is, nonetheless, a confounding continuum, laden with potentiality, more worthy of the human cultural project than any historically out-of-joint mechanical simulacrum. At its best, AMM carries out this function (subliminally or otherwise-maybe because of the power of the unconscious) by offering its most startling, surprising, and stimulating manifestation, turning listeners alternately towards a darkening world and other possible futures.

Consistency within transitional periods - politically, culturally, and artistically-is always likely to be variable and complex. Listen to Shostakovich's last quartet, completed in $1974 .{ }^{23}$ Parts of this are extremely modernist, 
heavily laced with romantic overtones-a mixed sonic message reflective of a conflicted artistic and political life. Socialist realism (a virulent form of social realism) has all the regressive marks applicable to the postmodern. A view of Shostakovich as "a master of many styles" is historically insufficient. His responses were surely an adaptive necessity towards the capricious and coercive climate of Soviet social realism, to which Shostakovich had been frequently subject, resulting in an intellectual house-arrest and the implicit threat of "re-education," forced labour, imprisonment, or worse.

Of course, the experience of music can transcend its production and ideology. "Sublime moments" (a woefully overused and misunderstood term) do not come attached to technical considerations. Nevertheless, in our reflections upon what we hear, there has to be discernment: meaning has to have an objective dimension beyond the sublime or the diverting. What can AMM music mean?

The practice of free improvisation-what I call a "meta-music" guided by creative responses to contingent events and conscious social agency-is where we dispense with what is culturally familiar as music, moving beyond the violence of the new. The compulsion to experiment arises because existing forms are inadequate to express things that concern a world in turmoil, yet the effects and results of experimentation are themselves vulnerable to the cannibalism of capital, fodder even for the postmodern: "[The] concept of experiment has, however, transformed itself in a fashion that is exemplary for the categories of the modern. Originally it meant simply that the will, conscious of itself, tested unknown or unsanctioned technical procedures" (Adorno 23).

The postmodern response is, on the one hand, a retreat from the treadmill of the imaginative process, and on the other hand a voracious coveter of "found" material. The "tyranny of the new" was feared as much as the violence of the experimental. It is easier to exploit the past or to subvert, corral, and safely neutralize the recently invented than to constantly search (the "modernist" agenda) for new solutions. ${ }^{24}$

The postmodern program sits comfortably under the rubric of reinvention-a faux-experimentalism. This fauxexperimentalism suggests a priority of style and orchestration over primary creativity. ${ }^{25} \mathrm{~A}$ counter-aesthetic legitimacy arises through Cardew's imaginative world of "informal sound," which includes our responses to the sounds of nature and industry (127). Implicitly, this is an ahistorical perspective: it steers the musician away from habit and the accretive sediment of second-nature culture towards a third-nature definition-a growing awareness of cultural conditioning. This awareness can produce a reasoned rejection of the aesthetic and political determinism of Thatcherism (often encompassed in the phrase "there is no alternative," or TINA): "Fundamental to this idea of experimentation was the latently traditionalistic belief that it would automatically become clear whether the results were a match for what had already been established and could thus legitimate themselves" (Adorno 23).

It thus behooves the improvising musician to be fully historical (to emerge from a "latently traditionalistic belief"), moving experimentally towards a reengagement with the unknown (but perhaps "knowable") qualities of materiality while concurrently searching for potential social forms: "Men make their own history, but they do not make it as they please; they do not make it under circumstances of their own choosing, but under circumstances existing already, given and transmitted from the past" (Marx 96).

How then has AMM maintained its existence for fifty years (and counting)? Was it detached, immune, or merely swimming in the prevailing tides of the time? For it too has its internal disputes, disagreements, and schisms: it was hardly plain sailing. Conventional outlets, some of whom were previously sympathetic to our albeit severe aesthetic agenda, now found AMM music a step too far.

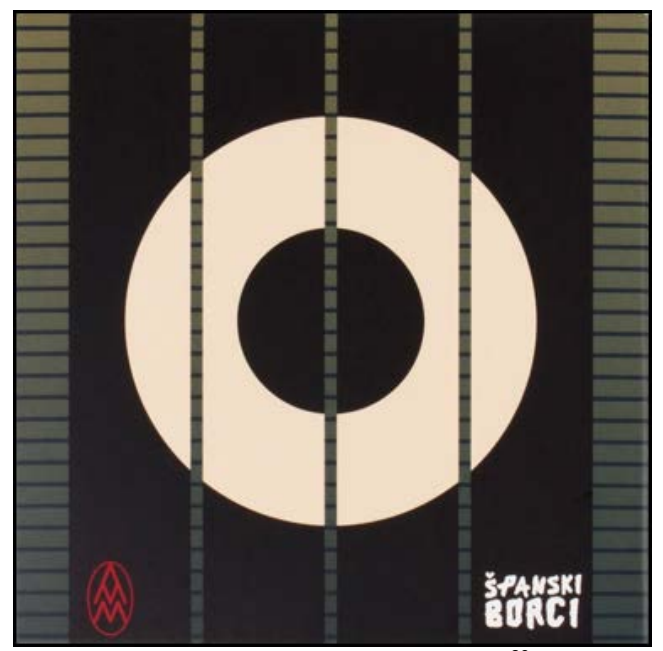

Click image above to listen to Track 3 from Spanish Fighters. ${ }^{26}$ [Adobe software may be required.] 
As suggested above, neoconservatism ${ }^{27}$ and the postmodern are interdependent and inveigle their way into the public mindset through a miasma of meaning. They share a deep mistrust of another misty idea: the shattered shibboleth of the left that is "progress"-or goal-oriented purposiveness. Previously, Marxist philosophy and modernism (although not necessarily completely compatible) were yoked together in a teleological tangle of means and ends, both condemned for inherent human failings, historically and philosophically visible to those who wished to see.

The Soviet economic model was difficult to defend because of its manifest flaws, deficiencies, and unexpected inequalities. This was attributed by neo-con outriders (perhaps rather too triumphantly) to an albeit vulgar form of Marxist economic determinism. TINA, however, proved to be no less deterministic. At the same time, many of the artistic apostles of modernism were losing their faith. Alongside the increasing difficulty of supporting the "progressive" ideas of various political and economic experiments derived (often controversially) from Marxist philosophy was the inherent danger of a US war machine that led President Eisenhower to warn (in his farewell address on January 17, 1961) against the Military-Industrial Complex. This danger, the Vietnam War, and the rush of US consumerism made many modernists, including Philip Guston, look askance at their own activities:

So when the 1960s came along I was feeling split, schizophrenic. The war, what was happening to America, the brutality of the world. What kind of man am I, sitting at home, reading magazines, going into a frustrated fury about everything —and then going into my studio to adjust a red to a blue. I thought there must be some way I could do something about it. I knew ahead of me a road was laying. A very crude, inchoate road. I wanted to be complete again, as I was when I was a kid . . Wanted to be whole between what I thought and what I felt. (qtd. in Storr 53)

Closer to home, Cardew rejected the socially insular and inhospitable traits of modernism by repudiating his own avant-garde compositions in favour of direct political action, identifying with class concerns beyond those of his parents, education, and previous apolitical interests and affiliations. ${ }^{28}$

New certainties were forged from revisionist histories of the Right. Aspects of the past commended reinvented value systems. A chokehold on the cultural life held by these two callings was achieved by a new twist on neoclassicism (which is inherently regressive): an aggressive reassertion of property rights and free market policies that gave each absolutist status.

I live close to John Locke's final resting place. It is a minor pilgrimage point for US citizens who know their constitutional history. Neo-con ideology derives its theoretical blend partly from Locke's treatment of the idea of property. This was the necessary intellectual and legal grounds for the new property-owning cadre who emerged from England's Tudor reconstruction of feudalism. Mixing one's energy with material was the moral foundation for claiming property. ${ }^{29}$ This possessive individualism became the rationale for property-owning democracies and a proposition that loses traction progressively with universal suffrage and the diminishing of material and conditions from which to make a profit. The $17^{\text {th }}$ century freedom to own property was justified through the existence of the supposedly "virgin lands" of the New World. Claimants to this territory apparently did not even see the First Nations peoples living there, presumably due to the absence of any deeds.

A "property owning" democracy is the linchpin of the current neoconservative project, supporting the newly revived idea that only property owners should qualify for the political franchise. ${ }^{30}$ Locke's view of democratic government (which many believe validate US political freedoms) was that only property-owners could be accredited with citizenship. Servants and other dependents (including wives) had no significant rights in the newly emergent polity. This exploitative social structure was an enduring prop for slavery (as an expression of private property) and misogyny.

It is difficult and possibly dangerous to put one's faith in "methods whose objective results cannot be foreseen" (Adorno 24) involving the collective "searching for sounds" (Cardew 27). Unforeseen results are exactly what opponents of modernism fear. It matters not if neoconservative propagandists and postmodern protagonists sleepwalk backwards, fostering a comforting, nostalgic, reinvented past. Fatalism is preferred to creative uncertainty. Modernism's frank admission that it does not know what the future holds is alternately attacked or diminished as vacuous, exploited as cultural madness and political weakness, while the refusal of postmodernism to imagine possible futures leads inevitably to inaction, and worse to the continuation of regressive and repetitive responses (often in the guise of the reinvented) through which vested socioeconomic interests flourish unchecked. ${ }^{32}$

Historically, the modernist agenda, of which experimentalism was an intrinsic part, failed to resist the reversal of market forces enforced by state power and was thereby washed away into the backwater of contemporary cultural life. ${ }^{33}$ There was some active resistance: Guston turned away from abstraction towards a gritty, figurative characterization of social and political reality, and Cardew turned to communist street politics, as did Keith Rowe for a couple of years. Others became accustomed to growing indifference: this was stasis, a capitulation. Some 
moved camp, made accommodations, and found survival opportunities within the new orthodoxy. Many experimentalists, of course, gave up and soundlessly disappeared-the ideal solution for those promoting the postmodern agenda. There has remained, however, a rump of awkward customers who see other values and freedoms than what is on offer in this "pick-and-mix" cultural reinvention of the postmodern.

A recurring topic during AMM's "on the road" conversations was to surmise what Cornelius would be doing. He made waves when alive. Despite his tragic and premature death in 1981, he still makes waves, as my account of his ideas herein supports. He certainly would not have acquiesced to the present state of affairs. I cannot presume to speak for Cornelius; I do, however, echo some of his earlier analyses and recommendations. These echoes do not recall the kind of social and political reconstruction he envisaged during the late 1970s and early 1980s. Times have moved on, and I (like many) do not have the disposition, perspective, or physical courage of a political revolutionist. That being said, I do not accept that postmodernism represents the end of historical optimism. ${ }^{34}$ Despite the official commercial art complex that marginalizes-in particular-the experimental, a modernist agenda still holds interest for many enquiring minds. This is evident through my own experience with the five hundred or so people who have attended the London workshop I first convened in 1999 and the many musicians I have worked with in numerous workshops in other countries. ${ }^{35}$ The postmodern cultural hegemony produces linguistic determinism where oppositional forces "wish" things into oblivion. Despite such efforts, however, and the commands of the airwaves and "opinion forming" mechanisms, a sizable ensemble of thoughtful people disregard, actively deride, and confound this attempt to tip them into the dustbin of a bogus historical discourse.

I see postmodernism as not simply an aggressive interruption of historicism, but an attempt to devalue the study of (and the lessons learned from) history itself. ${ }^{36}$ Far from an autonomous and free movement of ideas in some natural and neutral hurly-burly of intellectual ferment, postmodernism was and is a capitulation to the neoconservative remodeling of the world, the end of history mirrored and magnified by the death of art, the dictum of economic dictatorship, "there is no alternative" violently prevailing. Popularly, postmodernism (at its best) is an attractively accessible diversion requiring no meditation upon its meaning. It is outwardly concerned with elegance of form and technical competence, and its own iconic references are located more in the entertaining historical novella than in any verifiable "historical narrative"-which is actively demoted as a serious subject for study. ${ }^{37}$

Courage is required to discard the "certainties" of convention and the current market-led determinism (TINA), the neoconservative project with its showy and shadowy servant the postmodern. AMM, in its small way, has held on to its practices during the hastening and continuing flow of these twin false and deleterious nostrums. The experimental wing of modernism was never in hock with goal-oriented purposiveness. How could it be, if its practice foresaw that specific results were impossible to predict? Encouraging serendipity surely discomforts the idea of a "master narrative."

The experimental is not an abnegation of cultural responsibility; it is a secure and open creative foundation. Of course, it needs a historical sensibility to note past moments and assess present needs. This is far from being in thrall to the blind historicism of modernism. The searching musician is also free (although aware) of the ahistorical, nostalgic eclecticism of neoconservatism and the postmodern that contaminates cultural and economic life with its inherent poverty of imagination.

An enquiring aesthetic feeds and sustains an outward looking world view in which we dare to imagine the priorities of curiosity, care, and cooperation, superseding (beyond the mere negating of a negative) the current false and allegedly irreplaceable ideology of exploitation, control, and hierarchy. ${ }^{38}$ These clusters of opposing imperatives are means and not ends. Even Marx was not fool enough to suggest what a post-capitalist society would be like. At present, we are offered a nostalgia-tinged option of the devil we know. Unfortunately, the current Prince of Darkness is looming so large as to smother any other devil in its shade.

My young colleague Seymour Wright signs off his emails by saluting the future. He does not know what it will bring, but we know it will be both challenging and inescapable.

\section{Postscript}

In November 2015, AMM celebrated a $50^{\text {th }}$ anniversary concert at The Huddersfield Festival of Contemporary Music. It was marked by Keith Rowe rejoining the ensemble-with John Tilbury and Eddie Prévost-after a period of eleven years. Since then, there have been several other concerts. This rapprochement hopefully marks a further phase in AMM's creative trajectory, one firmly rooted in-and fervently projecting-a confident experimental aesthetic. 


\section{Notes}

${ }^{1}$ First released in 1967 on Elektra, and later re-released with additional material from the recording session as a CD in 1989 (ReRMegacorp). A new vinyl version was also released early in 2016 (Black Truffle Records).

2 This text, Cornelius Cardew: A Reader, and most of AMM's commercially available recorded output can be accessed through www.matchlessrecordings.com.

${ }^{3}$ Selecting material to accompany this article-which refers to 50 years of AMM-was not easy. Any single performance usually embraces a wide range of sounds and emotions. AMM performances are long, often lasting an hour or more, and very little of AMM's recorded output has been studio-based. During these engagements, instrumental identities are mostly obvious, but at times the voices merge or transform and it often becomes difficult to identify the source of particular musical moments. The choice of material is therefore mostly guided by historical factors.

4 “Improvisation: 'Music for an Occasion." British Journal of Music Education, vol. 2, no. 2, 1985, pp. 177-186. Later reprinted in No Sound is Innocent.

${ }^{5}$ There were those in attendance more supportive of my general thesis.

${ }^{6}$ In Cornelius Cardew: A Reader.

${ }^{7}$ Recorded live at The Great Hall at Goldsmiths' College, London in 1982-featuring me, John Tilbury, and Keith Rowe. The Great Hall is now available as disc 2 of the triple CD set Laminal, released by Matchless Recordings in 1996 to mark AMM's 30th anniversary retrospective.

8 "Meta-music" is a term I use to distinguish the experimental improviser from those disposed to treat their music more conventionally.

${ }^{9}$ A memorable phrase constructed by Seymour Wright and first used in his CD notes for Penumbrae (Jennifer Allum and Eddie Prévost, Matchless Recordings, 2011).

${ }^{10}$ There is much anthropomorphizing going on in describing the sounds of birds, insects, seals, and whales as "singing."

${ }^{11}$ Tilbury's Cornelius Cardew: a life unfinished offers the most comprehensive account of these events so far.

${ }^{12}$ An account and analysis of the concert and subsequent recording is contained in the chapter "Simulacrum?-A Case Study" from my book Minute Particulars (pp. 73-81). Here, John Tilbury contemplates his pianistic role as "victim" facing annihilation from "engulfing sound." Possible death at the hands of Caravaggio might seem ironic, given that the painter had been ordered executed by the Pope after he killed a man.

13 "The audience, at whom our music was supposed to be directed, would be made up of experts. The public would be excused from attending our concerts; in other words, our public would be the press and our protectors." (Hans Werner Henze. "German Music in the 1940s and 1950s." Music and Politics; Collected Writings (1953-81). Translated by Peter Labanyi, Cornell UP, 1982, p. 40).

${ }^{14}$ Gold from Spanish expeditions to America and British receipts of empire by way of cotton and sugar I now see as incidental to funding of the Enlightenment (e.g. Darwin's inclusion on the British Admiralty's Beagle surveying mission) and the development of the Industrial Revolution.

15 "Plunderphonics, or Audio Piracy as a Compositional Prerogative," presented to the Wired Society ElectroAcoustic Conference in Toronto, 1985.

${ }^{16}$ According to Richard Taruskin, historical precedents for postmodernism can be set earlier than the late 20th century to Rochberg, Crumb, Lerdahl, and Schnittke (Music in the Late Twentieth Century, Oxford UP, 2010). I think one can go back very much further to make earlier proto-postmodern comparisons. The point is postmodernism was of no cultural use until neoconservativism began to gain momentum. 
17 Jim O'Rourke's treated recordings are not analogous to Keith Rowe's predominant use of spontaneous and randomly acquired radio output.

${ }^{18}$ cod: British slang for fake.

${ }^{19}$ The black American aspirational classes invested their support in the USA's main claim to an indigenous art form (i.e. jazz). In this they celebrate the highly individualistic achievements that arose from the sophisticated and almost technocratic competence residing in bebop jazz, now personified most closely with the sepia retrospective output of Wynton Marsalis. There is a reluctance in US civil society to extend the economic, social, and political enfranchisement to all sectors of the black community. There are, of course, charitable outreach programs from institutions like the Lincoln Center. These and other benefactory initiatives associated with the rich in the USA are ameliorative in their affect, but little is done to give structural social and economic relief. When Pope Francis cautions the rich within his American flock against self-regarding charity, manifest in balls and fund-raising banquets and concerts, one senses that something is fundamentally wrong.

${ }^{20}$ Matchless Recordings, 1992.

21 "Improvisation" does not figure at all in Adorno's and Taruskin's discussions of "the experimental."

${ }^{22}$ Among others, Evan Parker and I served at different times on the Arts Council's "new music subcommittee" during the 1980s. Few, if any, of the new "arts administrators" had any performance experience in the arts they became responsible for.

${ }^{23}$ String Quartet No. 15 in E-flat minor, Op. 144.

${ }^{24}$ The postmodern: an aesthetic complex so wanting of creativity that it can only be described by referring to what it is not (i.e. not modern). Its credo-and credentials-are contingent upon negating the perceived negativity (the creative, intellectual, and potential political force) of modernism.

${ }^{25}$ A contrast needs to be made between reinvention and self-invention. One cannot reinvent the wheel. It may, of course, be possible to creatively rework the wheel concept, but its essential "wheelness" remains intact. Various examinations of this idea arise in my books.

${ }^{26}$ Recorded live at the Neposlusno (Sound Disobedience) festival in Spanski borci in Ljubljana, Slovenia on 16 November 2012. AMM's most recently released CD (Matchless, 2015) featuring me and Tilbury. (None of our recordings, it seems to me, are representative. In the 1980s, critic David llic remarked that "AMM albums are as alike and unalike as trees.")

${ }^{27}$ Readers may think the use of the term "neoconservative" is unusual. It replaces the more current term "neoliberalism" when engaging with the global capitalist thrust of the past forty years or so. My reasons for using the term are these: Bernie Sanders's assertions that we are enmeshed in a system of "rigged markets," and the persuasive examples and arguments of Guy Standing, whose book The Corruption of Capitalism leads one to believe that the current world economic environment is the most "unfree" market that has ever been. If this is so, then obviously the use of the term "liberalism" (which has some positive connotations within Enlightenment thinking) is misplaced, and its current use confuses. It seems to me, therefore, what we are reckoning with is the protection of economic advantages: hence, my preferred use of the term "conservatism." In nineteenth century Britain, for instance, there was a struggle to repeal the Poor Laws and the Corn Laws. Both repeals were deemed as necessary conditions for the freedom of labour that would advance industrial capitalism-in particular, the cotton factories. Resistance came principally from the aristocracy and large land owners who wished to maintain a high price for their crops (mainly corn, which could often be obtained more cheaply from foreign imports) and retain their labour force through a system of minimal subsistence benefit known as the Speenhamland system, whereby farm labourers were tied to their home locality in fear of losing their subsistence payments in workless times. In short, this was a conservative resistance to changes that would give advantage only to the newly emergent entrepreneurial class. The current economic settlement bears comparison in that rent and depression of income for the majority of workers is to the advantage primarily of the rentier class, which is inherently restrictive, uncompetitive, and negative in its productive power. Therefore, I would argue, it is technically "conservative."

${ }^{28}$ Tilbury's monumental biography captures the commitment, personal risk, and frustration inherent in Cardew's efforts to counter capitalist hegemony. 
${ }^{29}$ See Locke's Two Treatises of Government (1689).

${ }^{30}$ After all, why would non-property owners have any interest in preserving the rights and entitlements that go with property and its wealth accruing (capitalist) qualities?

${ }^{31}$ A further example of the dubiety of revisionist right wing history can be found in Adam Smith's concept of the "invisible hand of the market," first published in 1759 in The Theory of Moral Sentiments. This natural, spontaneous sense of market forces effecting unintended consequences was thought of as inherently natural, neutral, good, and fair-but was significantly conceived "before" limited liability was introduced into American law, which necessarily interrupts the so-called spontaneity of market forces.

${ }^{32}$ This kind of appraisal also applies (although less controversially) to pure science.

${ }^{33}$ Britain, Conservative grandee Lord Hailsham triumphantly claimed, was "an elective dictatorship" (Richard Dimbleby Lecture. BBC, 1976).

${ }^{34}$ Although I do accept that many modernists lost their nerve.

${ }^{35}$ The London workshop is completely self-sufficient and has never "promoted" its existence.

${ }^{36}$ During the early years of her premiership, Margaret Thatcher infamously censured a graduate student for studying history. This attitude has been reflected and amplified in subsequent neoconservative policies towards education, part of the postmodern's "dumbing-down" agenda.

${ }^{37}$ Fukuyama's article "The End of History?" chimes with this debate, i.e. the postmodern as a bolstering cultural support for neo-conservatism. All one can do within this "new reality" is tinker with the existing model. This goes for music and the arts, as well as socioeconomic structures. Is the die cast for all time? What need is there to study history-or make new music?

${ }^{38}$ This appraisal goes someway, I hope, to counter the oft repeated claim that improvisation is a vehicle of the self-absorbed and solipsistic. Maybe those of that persuasion can disguise themselves with an experimental veneer; however, as Cardew notes, music also "has a power over our emotional responses ... [in] that it acts subliminally rather than on a conscious cultural level" (127).

\section{Works Cited}

Adorno, Theodor. Aesthetic Theory. Athlone, 1999.

AMM. The Crypt. Matchless Recordings, 1968.

Boulez, Pierre. Orientations. Faber and Faber, 1986.

Cardew, Cornelius. "Towards an Ethic of Improvisation." Cornelius Cardew: A Reader, edited by Edwin Prévost, Copula, 2006.

Fukuyama, Francis. "The End of History?” The National Interest, Summer 1989, pp. 3-18.

Marx, Karl. "The Eighteenth Brumaire of Louis Bonaparte." Selected Works, Vol. 1. Lawrence and Wishart, 1977.

Mithen, Stephen. The Prehistory of the Mind. Phoenix, 1998.

Prévost, Edwin. Minute Particulars. Copula, 2004.

---. No Sound is Innocent. Copula, 1995. 
Critical Studies in Improvisation / Études critiques en improvisation, Vol. 11, Nos. 1-2

Rowe, Keith, composer. The Hands of Caravaggio. Performance by MIMEO and John Tilbury. Erstwhile Records, 2002.

Storr, Robert. Guston. Abbeville, 1986.

Tilbury, John. Cornelius Cardew: a life unfinished. Copula, 2008.

---. Liner Notes. Material Consequences, performance by Eddie Prévost, Matchless Recordings, 2001. 